\title{
Endoscopic internal drainage using double-pigtail stent placement to manage a case of proximal colo-colonic anastomotic leakage
}

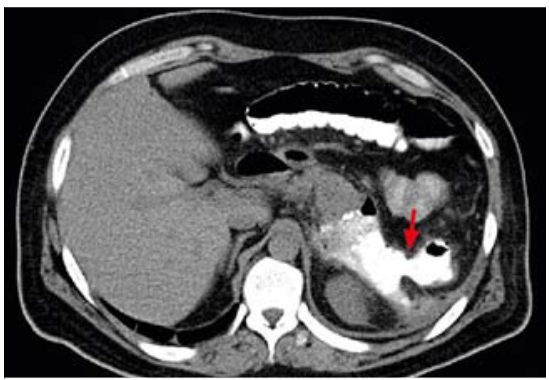

- Fig. 1 Computed tomography scan showing an extra-luminal contrast-medium passage (red arrow) from the left colonic anastomotic region to the intra-abdominal collection located in the splenic loggia.

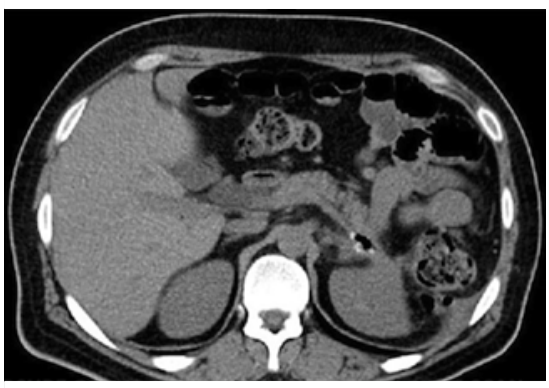

Fig. 3 Computed tomography scan showing a complete collapse of the peri-anastomotic collection after stent removal.

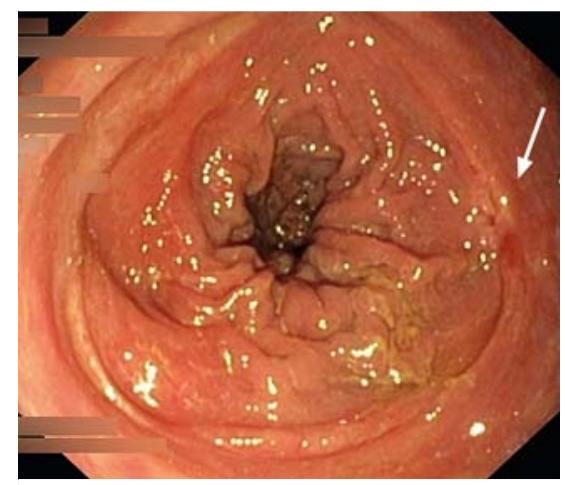

Fig. 4 Endoscopic view of regular colocolonic anastomosis with a complete closure of the leak orifice (arrow) at 6-month follow-up.
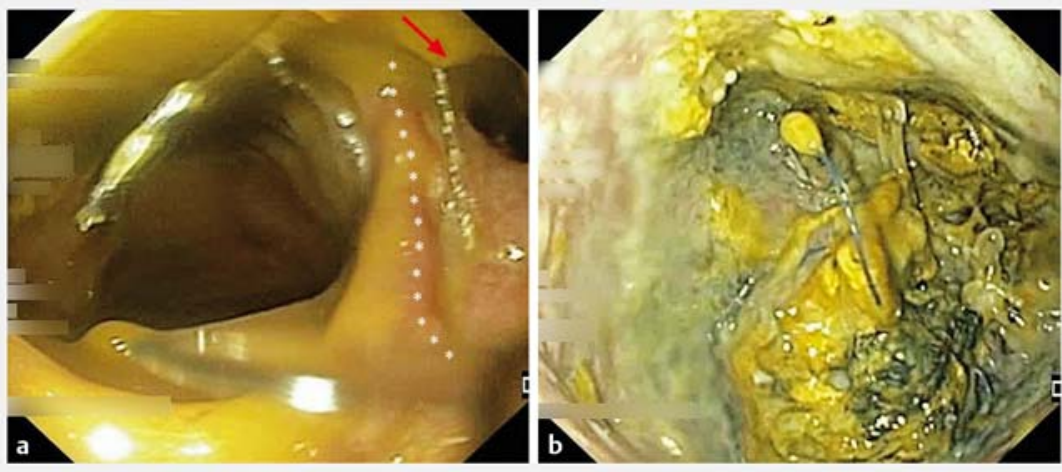

Fig. 2 Endoscopic views. a Leak (asterisks) of the colo-colonic anastomosis with an orifice (red arrow). b Wide peri-anastomotic cavity accessed through the orifice.

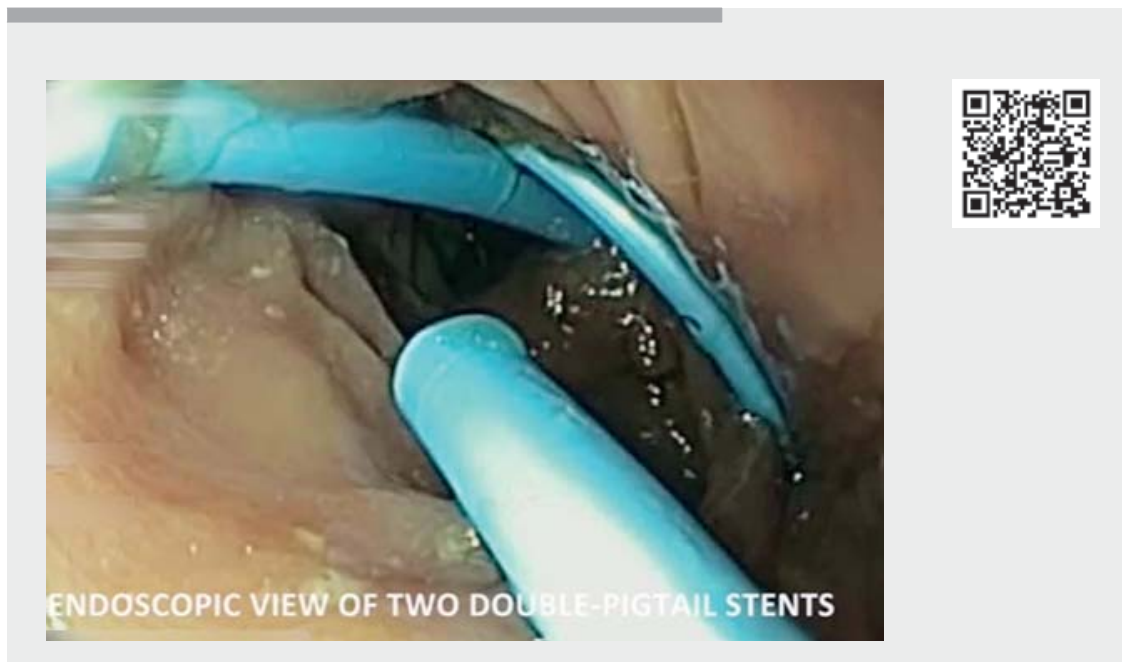

$\checkmark$ Video 1 Endoscopic internal drainage using double-pigtail stent placement to manage proximal colo-colonic anastomotic leakage. This approach works by promoting collapse of the collection, granulation-tissue formation and re-epithelization of the leak orifice

A 39-year-old man underwent a distal spleno-pancreatectomy and colonic resection for a tail pancreatic cancer infiltrating the colonic splenic flexure. Five days after surgery, the patient experienced fever and abdominal pain. A computed tomography (CT) scan showed a $10-\mathrm{cm}$ intra-abdominal collection with free air bubbles inside; oral contrastmedium intake revealed a passage from the colon to the abdominal collection, highly suspicious of an anastomotic leak ( Fig. 1).

Endoscopy confirmed a wide anastomotic leakage with access to a peri-anastomotic cavity ( $\mathbf{F i g . 2 a , b )}$ and we decided to attempt endoscopic internal drainage in order to avoid a new surgical procedure.

Under endoscopic view and fluoroscopic guidance, two double-pigtail plastic stents (10-Fr/10-cm and 7-Fr/7-cm, Bos- 
ton Scientific, Massachusetts, USA) were placed across the leak orifice ( $\vee$ Video 1 ) with one pigtail tip of each stent located inside the cavity. A CT scan 24 hours later confirmed the correct placement of the two stents.

Follow-up CT scans showed a progressive reduction in the collection's size up to $2 \mathrm{~cm}$ at 5 weeks, so stent removal was planned. Endoscopy showed a closure of the anastomotic leak and a single stent "in situ" that was removed with a forceps. The next CT scan confirmed the complete collapse of peri-anastomotic collection ( Fig.3). After 6 months, the colo-colonic anastomosis appeared endoscopically regular with a complete closure of the leakage ( Fig.4).

Endoscopy is emerging as a first-line approach over surgery for management of post-operative gastrointestinal leaks and fistulae [1]. While endoluminal vacuum therapy is reported as an effective method for management of colo-rectal anastomotic leakages [2], endoscopic internal drainage by double-pigtail stent placement is described as a conservative treatment of leaks and fistulas after upper gastrointestinal surgery, especially in the bariatric setting [3-5]. The application of endoscopic internal drainage technique in this case allowed us to successfully and conservatively manage a proximal colo-colonic anastomotic leakage without needing a protective ileostomy or an additional surgical procedure.

Endoscopy_UCTN_Code_TTT_1AQ_2AG
Competing interests

Dr. Roberto Di Mitri is consultant of Boston Scientific; the other authors have no conflicts of interest.

The authors

Roberto Di Mitri ${ }^{1}$, Ambra Bonaccorso' ${ }^{1}$, Filippo Mocciaro' ${ }^{1}$, Michele Amata ${ }^{1}$, Elisabetta

Conte $^{1}$, Pierenrico Marchesa ${ }^{2}$, Daniela

Scimeca ${ }^{1}{ }^{\circ}$

1 Gastroenterology and Endoscopy Unit, ARNAS Civico - Di Cristina - Benfratelli Hospital, Palermo, Italy

2 Oncologic Surgery Unit, ARNAS Civico - Di Cristina - Benfratelli Hospital, Palermo, Italy

\section{Corresponding author}

Daniela Scimeca, MD, PhD

Gastroenterology and Endoscopy Unit, ARNAS Civico - Di Cristina - Benfratelli Hospital, Piazza N. Leotta n. 4, 90100,

Palermo, Italy

d.scimeca80@gmail.com

\section{References}

[1] Cereatti F, Grassia R, Drago A et al. Endoscopic management of gastrointestinal leaks and fistulae: What option do we have? World J Gastroenterol 2020; 26: 4198-4217

[2] Abdalla S, Cotte E, Epin A et al. Short-term and long-term outcome of endoluminal vacuum therapy for colorectal or coloanal anastomotic leakage: results of a nationwide multicenter cohort study from the French GRECCAR Group. Dis Colon Rectum 2020; 63: $371-380$
[3] Donatelli G, Dumont JL, Cereatti F et al. Endoscopic internal drainage as first-line treatment for fistula following gastrointestinal surgery: a case series. Endosc Int Open 2016; 4: E647-E651

[4] Gonzalez JM, Lorenzo D, Guilbaud T et al. Internal endoscopic drainage as first line or second line treatment in case of postsleeve gastrectomy fistulas. Endosc Int Open 2018; 6: E745-E750

[5] Donatelli G, Spota A, Cereatti F et al. Endoscopic internal drainage for the management of leak, fistula, and collection after sleeve gastrectomy: our experience in 617 consecutive patients. Surg Obes Relat Dis 2021; 17: 1432-1439

\section{Bibliography}

Endoscopy 2022; 54: E454-E455

DOI 10.1055/a-1625-4106

ISSN 0013-726X

published online 27.9.2021

(c) 2021. Thieme. All rights reserved.

Georg Thieme Verlag KG, Rüdigerstraße 14,

70469 Stuttgart, Germany

ENDOSCOPY E-VIDEOS

https://eref.thieme.de/e-videos

口回 Endoscopy E-Videos is an open access online section, 靣棰: reporting on interesting cases and new techniques in gastroenterological endoscopy. All papers include a high quality video and all contributions are freely accessible online. Processing charges apply (currently EUR 375), discounts and wavers acc. to HINARI are available.

This section has its own submission website at https://mc.manuscriptcentral.com/e-videos 